\title{
Analyst
}

CORRECTION
Cite this: Analyst, 2016, 141, 3444

DOI: 10.1039/c6an90037b

www.rsc.org/analyst

\section{Correction: Micropatterning neuronal networks}

View Article Online

View Journal | View Issue
Heike Hardelauft, ${ }^{a}$ Sarah Waidet, ${ }^{a}$ Julia Sisnaiske, ${ }^{\mathrm{b}}$ Peter Jacob, ${ }^{a}$ Vanessa Hausherr, ${ }^{\mathrm{b}}$

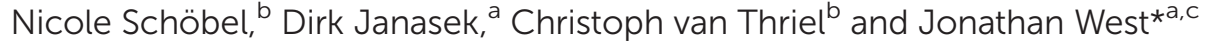

Correction for 'Micropatterning neuronal networks' by Heike Hardelauf, et al., Analyst, 2014, 139, $3256-3264$.

In the acknowledgements section the authors listed funding from a Bundesministerium für Bildung und Forschung grant BMBF 0101-31P6541, but it should read BMBF 0315545A.

The Royal Society of Chemistry apologises for these errors and any consequent inconvenience to authors and readers.

${ }^{a}$ Leibniz-Institut für Analytische Wissenschaften - ISAS - e.V., 44139 Dortmund, Germany

${ }^{b}$ Leibniz Research Centre for Working Environment and Human Factors - IfADo, 44139 Dortmund, Germany

${ }^{c}$ Institute for Life Sciences, University of Southampton, SO17 1BJ, UK. E-mail: J.J.West@soton.ac.uk 